\title{
Model physics and chemistry causing intermodel disagreement within the VolMIP-Tambora Interactive Stratospheric Aerosol ensemble
}

Margot Clyne $^{1,2}$, Jean-Francois Lamarque ${ }^{3}$, Michael J. Mills ${ }^{3}$, Myriam Khodri ${ }^{4}$, William Ball, ${ }^{5,7}$, Slimane 5 Bekki $^{8}$, Sandip S. Dhomse ${ }^{9}$, Nicolas Lebas ${ }^{4}$, Graham Mann ${ }^{9,10}$, Lauren Marshall ${ }^{9,11}$, Ulrike Niemeier ${ }^{12}$, Virginie Poulain ${ }^{4}$, Alan Robock ${ }^{13}$, Eugene Rozanov,6, Anja Schmidt ${ }^{11,14}$, Andrea Stenke ${ }^{6}$, Timofei Sukhodolov $^{5}$, Claudia Timmreck ${ }^{12}$, Matthew Toohey ${ }^{15,16}$, Fiona Tummon ${ }^{6,17}$, Davide Zanchettin ${ }^{18}$, Yunqian $\mathrm{Zhu}^{2}$ and Owen B. Toon ${ }^{1,2}$

$10{ }^{1}$ Department of Atmospheric and Oceanic Sciences, University of Colorado, Boulder, CO, USA

${ }^{2}$ Laboratory for Atmospheric and Space Physics, Boulder, CO, USA

${ }^{3}$ National Center for Atmospheric Research, Boulder, CO, USA

${ }^{4}$ LOCEAN, Sorbonne Universités/UPMC/CNRS/IRD, Paris, France

${ }^{5}$ PMOD WRC Physical Meteorological Observatory Davos and World Radiation Center, Davos Dorf, Switzerland

$15{ }^{6}$ Institute for Atmospheric and Climate Science, ETH Zurich, Switzerland

${ }^{7}$ Department of Geoscience and Remote Sensing, TU Delft, The Netherlands

${ }^{8}$ LATMOS/IPSL, Sorbonne Université, UVSQ, CNRS, Paris, France

${ }^{9}$ School of Earth and Environment, University of Leeds, Leeds, U.K.

${ }^{10}$ National Centre for Atmospheric Science, University of Leeds, UK

$20 \quad{ }^{11}$ Department of Chemistry, University of Cambridge, UK

${ }^{12}$ Max Planck Institute for Meteorology, Hamburg, Germany

${ }^{13}$ Department of Environmental Sciences, Rutgers University, New Brunswick, NJ, USA

${ }^{14}$ Department of Geography, University of Cambridge, UK

${ }^{15}$ Institute for Space and Atmospheric Studies, University of Saskatchewan, Canada

$25{ }^{16}$ GEOMAR Helmholtz Centre for Ocean Research Kiel, Kiel, Germany

${ }^{17}$ Swiss Federal Office for Meteorology and Climatology MeteoSwiss, Payerne, Switzerland

${ }^{18}$ Department of Environmental Sciences, Informatics and Statistics, Ca'Foscari University of Venice, Mestre, Italy

Correspondence to: Margot Clyne (Margot.Clyne@,colorado.edu) 


\section{Supplementary Info}

\section{S1 Derivation of Eqs. (1 and 2)}

This section shows how we adapted equations from Seinfeld and Pandis (2016) to derive our Eqs. (1 and 2). Arising from BeerLambert law, the generic optical depth is the integral of the extinction coefficient $\left(b_{\text {ext }}\right)$ over a path (e.g. through the atmosphere)

(e.g. Seinfeld and Pandis 2016 Eq. (4.13)). Assuming a constant $b_{e x t}$ over a path of length $z$ gives the layer optical depth $(\tau)$ :

$\tau=b_{\text {ext }} Z$

The extinction coefficient for a given wavelength $(\lambda)$ for particles ranging in diameter $\left(D_{p}\right)$ from 0 to $D_{p \max }$ is defined as:

$b_{\text {ext }}=\int_{0}^{D_{p \max }} E_{\text {ext }}\left(D_{p}, \lambda, m\right) n_{M}\left(D_{p}\right) d D_{p}$

(S2, Seinfeld and Pandis 2016 Eq. (15.40))

where $E_{\text {ext }}$ is the mass extinction efficiency (with function parameters of particle size, wavelength, and complex refractive index $(m)$ ), and $n_{M}\left(D_{p}\right)$ is the mass size distribution. The total mass of particles of all sizes per volume $\left(m_{p}\right)$ is:

$m_{p}=\int_{0}^{D_{p \max }} n_{M}\left(D_{p}\right) d D_{p}$

So by the Mean Value Theorem for definite integrals, the mean value over the mass size distribution of the mass extinction efficiency, $\left\langle E_{\text {ext }}\right\rangle$, is:

$\left\langle E_{\text {ext }}\right\rangle=\frac{\int_{0}^{D_{p \max }} E_{\text {ext }}\left(D_{p}, \lambda, m\right) n_{M}\left(D_{p}\right) d D_{p}}{\int_{0}^{D p \max } n_{M}\left(D_{p}\right) d D_{p}}=\frac{1}{m_{p}} \int_{0}^{D_{p \max }} E_{\text {ext }}\left(D_{p}, \lambda, m\right) n_{M}\left(D_{p}\right) d D_{p}=\frac{1}{m_{p}} b_{\text {ext }}$

45 So,

$b_{\text {ext }}=\left\langle E_{\text {ext }}\right\rangle m_{p}$

The mass extinction efficiency for spherical particles is:

$E_{\text {ext }}\left(m, D_{p}, \lambda\right)=\frac{3}{2 \rho_{p} \boldsymbol{D}_{\boldsymbol{p}}} Q_{\text {ext }}(m, \alpha)$

(S6, Seinfeld and Pandis 2016 Eq. (15.41))

which comes from the dimensionless extinction efficiency of a particle $\left(Q_{e x t}\right)$ as a function of complex refractive index $(m)$ and

optical size parameter $\left(\alpha=\frac{\pi D_{p}}{\lambda}\right)$, and the ratio of cross sectional area to mass $\left(\frac{3}{2 \rho_{p} D_{p}}\right)$ where $\rho_{p}$ is the particle density. Maintaining the notation of " $<$ brackets $>$ " to denote the mean value over the mass size distribution:

$\left\langle E_{\text {ext }}\right\rangle=\left\langle\frac{3}{2 \rho_{p} D_{p}} Q_{\text {ext }}\right\rangle$

For a monodisperse population (e.g. if the aerosols were of uniform size), Eq. (S7) would simply be:

$\left\langle E_{\text {ext }}\right\rangle=\frac{3}{4 \rho_{p} r_{p}} Q_{\text {ext }}(m, \alpha)=E_{\text {ext }}$

55 where $r_{p}$ is the particle radius. However, since the aerosols are polydisperse, we must account for the different sizes of the aerosols in Eq. (S7). By the proof in the subsequent section (Sect. S1.1), we have:

$\left\langle\rho_{p} r_{p}\right\rangle=\left\langle\rho_{p}\right\rangle r_{e f f}$

And if we assume:

$\left\langle Q_{\text {ext }}\left(m, \alpha\left(\lambda, r_{p}\right)\right)\right\rangle \approx Q_{\text {ext }}\left(m, \alpha\left(\lambda, r_{\text {eff }}\right)\right)$, which we denote as $Q_{\text {ext }}\left(r_{\text {eff }}\right)$ 


$$
\begin{array}{rlr}
\left\langle E_{\text {ext }}\right\rangle= & \frac{3}{4\left\langle\rho_{p}\right\rangle r_{\text {eff }}}\left\langle Q_{\text {ext }}(m, \alpha)\right\rangle & \text { (by Eq. (S9)) } \\
& \simeq \frac{3}{4\left\langle\rho_{p}\right\rangle r_{\text {eff }}} Q_{\text {ext }}\left(r_{e f f}\right) & \text { (by Eq. (S10)) }
\end{array}
$$

We note that the approximate equation for polydisperse aerosol, Eq. (S11b), becomes exact for monodisperse aerosol.

65 The mass extinction efficiency $\left(E_{\text {ext }}\left(m, D_{p}, \lambda\right)\right)$ can be written in units of $\left[\mathrm{m}^{2} / \mathrm{g} \mathrm{SO}_{4}{ }^{2-}\right]$ for sulfate-containing particles by writing the particle density $\left(\rho_{p}\right)$ in units of $\left[\mathrm{g} \mathrm{SO}_{4}{ }^{2-} / \mathrm{m}^{3}\right]$. The mass extinction efficiency is the same as the mass scattering efficiency for sulfate aerosols because there is no absorption. Seinfeld and Pandis (2016) write this mass extinction efficiency as $\alpha_{S O_{4}^{2-}}$ (not to be confused with the notation for the optical size parameter in Eqs. (S6 to S11a)) and call it the light-scattering mass efficiency of the aerosol for sulfate-containing particles. For a sulfate aerosol layer of vertical pathlength $H(\mathrm{~m})$, the aerosol optical depth $(\tau)$ in

70 Seinfeld and Pandis (2016) is expressed as Eq. (S12), which comes from Eq. (S1).

$\tau=\alpha_{\mathrm{SO}_{4}^{2-}} m_{\mathrm{SO}_{4}^{2-}} \mathrm{H}$

(S12, Seinfeld and Pandis 2016 Eq. (24.24))

where $m_{\mathrm{SO}_{4}^{2-}}$ is the mass aerosol concentration in units of $\left[\mathrm{g} \mathrm{SO}_{4}{ }^{2-} / \mathrm{m}^{3}\right.$ ] (not to be confused with the notation for the complex refractive index in Eqs. (S2 to S11a)). The mean column aerosol optical depth ( $\bar{\tau}$ ) (which in our case is the stratospheric optical depth), is similarly expressed in Seinfeld and Pandis (2016) as:

$75 \bar{\tau}=\alpha_{S O_{4}^{2-}} \overline{m_{S O_{4}^{2-}}}$

(S13, Seinfeld and Pandis 2016 Eq. (24.27))

where $\overline{m_{\mathrm{SO}_{4}^{2-}}}$ is the column burden of sulfate aerosol in units of $\left[\mathrm{g} \mathrm{SO}_{4}{ }^{2-} / \mathrm{m}^{2}\right]$.

The expressions pulled from Seinfeld and Pandis (2016) thus far have been describing the dehydrated sulfate aerosol. Sulfuric acid particles are always hydrated, so we need to account for the water component of the sulfate aerosol in our expression for aerosol optical depth. Seinfeld and Pandis (2016) do this by scaling $\alpha_{\mathrm{SO}_{4}^{2-}}$ by a factor which is a function of relative humidity to account for the change in the scattering cross section with the presence of water (Seinfeld and Pandis, 2016 Eq. (24.25)). We use the following method instead. Equation (S6), which is Eq. (15.41) in Seinfeld and Pandis (2016), is given in terms of the particle component of the aerosol only, but we can convert to the full wet sulfate aerosol $\left(\mathrm{H}_{2} \mathrm{O}-\mathrm{H}_{2} \mathrm{SO}_{4}\right)$ by using the mean wet particle radius (which is the effective radius, Reff) instead of the dry particle diameter, $D_{p}$, and using the density, $\rho$, of the full wet sulfate aerosol $\left[\mathrm{g} \mathrm{H}_{2} \mathrm{O}-\mathrm{H}_{2} \mathrm{SO}_{4} / \mathrm{m}^{3}\right.$ ] instead of just the density of the sulfate particle component, $\rho_{p}$, [g $\mathrm{SO}_{4}{ }^{2-} / \mathrm{m}^{3}$ ]. We also want our equation in terms of the column mass burden of $\mathrm{S}$, because we are tracking the mass of $\mathrm{S}$ in the model outputs instead of tracking the mass of $\mathrm{SO}_{4}{ }^{2-}$. Thus, we write:

$A O D=\alpha_{S} \frac{M}{A}$

where $\alpha_{S}$ is the aerosol mass extinction coefficient in units of $\left[\mathrm{m}^{2} / \mathrm{g} \mathrm{S}\right]$, and $M$ and $A$ are the stratospheric mass burden of sulfate 90 aerosol and surface area of the Earth, giving the second term units of $\left[\mathrm{g} \mathrm{S} / \mathrm{m}^{2}\right.$ ]. These quantities are related to those in Eq. (S13, Seinfeld and Pandis 2016 Eq. (24.27)) by:

$\frac{M}{A}=\overline{m_{S O_{4}^{2-}}} \frac{(\text { molec.weight } S)}{\left(\text { molec.weight } \mathrm{SO}_{4}^{2-}\right)}$ 
$\alpha_{S}=\frac{\left.3 Q_{\text {ext }} \text { (molec. weight } \mathrm{H}_{2} \mathrm{SO}_{4}\right)}{4 \rho \text { Reff }(\text { molec. weight } \mathrm{S})} \frac{\left[\mathrm{H}_{2} \mathrm{O}-\mathrm{H}_{2} \mathrm{SO}_{4}\right]}{\left[\mathrm{H}_{2} \mathrm{SO}_{4}\right]}=\frac{\left.3 q \text { (molec. weight } \mathrm{H}_{2} \mathrm{SO}_{4}\right)}{4 \rho \text { Reff } \text { (molec. weight } \mathrm{S}) \omega}$

Rearranging gives our derived Eqs. (1 and 2) from the main text:

$95 \quad \psi=\frac{3 q}{4 \rho \mathrm{A}} \frac{\left(\text { molec.weight } \mathrm{H}_{2} \mathrm{SO}_{4}\right)}{(\text { molec.weight } \mathrm{S}) * \omega}$

and

$A O D=\psi * \frac{M}{\operatorname{Reff}}$

\section{S1.1 Proof of Eq. (S9)}

The mass size distribution $\left(n_{M}\right)$ for spherical particles of diameter $D_{p}$ is related to the number size distribution $(n)$ by:

$100 n_{M}\left(D_{p}\right)=\frac{\pi}{6} \rho_{p} D_{p}^{3} n\left(D_{p}\right)$

(S16, Seinfeld and Pandis 2016 Eq. (8.8))

So,

$n\left(r_{p}\right)=\frac{3}{4 \pi \rho_{p} r_{p}^{3}} n_{M}\left(r_{p}\right)$

recall from Appendix A that:

$r_{e f f}=\frac{\int_{r \min }^{r \max } r \pi r^{2} n(r) d r}{\int_{r \min }^{r \max } \pi r n(r) d r}$

105 Plugging in Eq. (S17) and assuming for now that $r_{p}$ can be substituted for $r$ yields:

$r_{e f f}=\frac{\frac{3}{4 \pi} \int \frac{r_{p} \pi r_{p}^{2}}{\rho_{p} r_{p}^{3}} n_{M}\left(r_{p}\right) d r_{p}}{\frac{3}{4 \pi} \int \frac{\pi r_{p}^{2}}{\rho_{p} r_{p}^{3}} n_{M}\left(r_{p}\right) d r_{p}}=\frac{\int \frac{1}{\rho_{p}} n_{M}\left(r_{p}\right) d r_{p}}{\int \frac{1}{\rho_{p} r_{p}} n_{M}\left(r_{p}\right) d r_{p}}$

All of the integrals in Eqs. (S18 and S19) are actually definite integrals (i.e. bounded by the minimum and maximum radius values defined in the model's size distribution). Applying the Mean Value Theorem for definite integrals to Eq. (S18) yields:

$r_{e f f}=\frac{\int \frac{1}{\rho_{p}} n_{M}\left(r_{p}\right) d r_{p}}{\int n_{M}\left(r_{p}\right) d r_{p}} * \frac{\int n_{M}\left(r_{p}\right) d r_{p}}{\int \frac{1}{\rho_{p} r_{p}} n_{M}\left(r_{p}\right) d r_{p}}=\frac{\left\langle\frac{1}{\rho_{p}}\right\rangle}{\left\langle\frac{1}{\rho_{p} r_{p}}\right\rangle}=\frac{\left\langle\rho_{p} r_{p}\right\rangle}{\left\langle\rho_{p}\right\rangle}$

110 therefore,

$\left\langle\rho_{p}\right\rangle r_{e f f}=\left\langle\rho_{p} r_{p}\right\rangle$

where $\left\langle\rho_{p}\right\rangle$ is the mean particle density of the mass size distribution, $\left\langle\rho_{p} r_{p}\right\rangle$ is the mean value of (particle density times radius) of the mass size distribution, and $r_{\text {eff }}$ is the local effective radius. 


\section{Global Stratospheric Sulfur Burden}

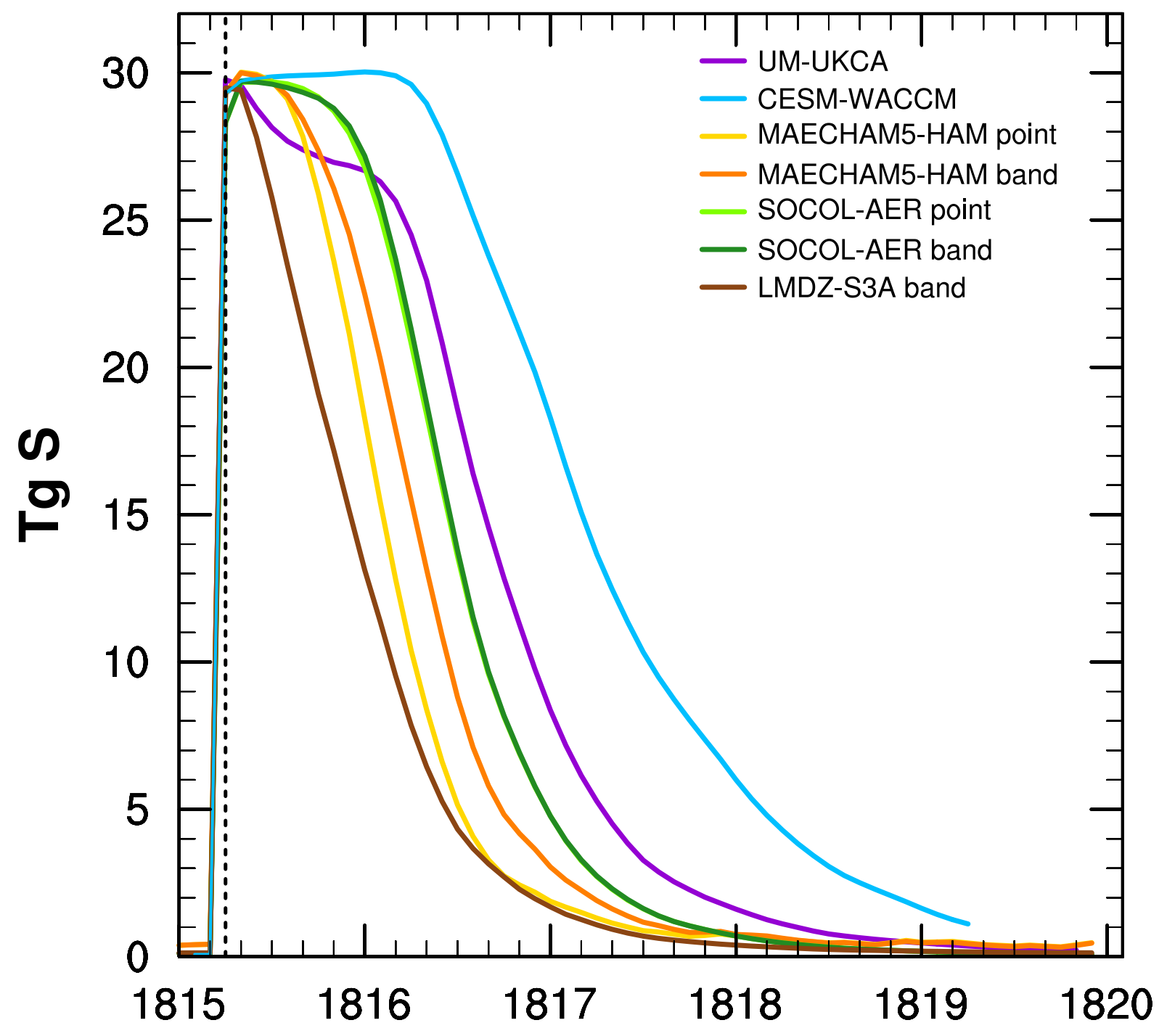

Figure S1: Global stratospheric burden of sulfur species $\left(\mathrm{SO}_{2}+\mathrm{H}_{2} \mathrm{SO}_{4}+\mathrm{SO}_{4}\right)$ in TgS vs time for CESM-WACCM (blue), UM-UKCA (purple), SOCOL-AER point (light green), SOCOL-AER band (dark green), MAECHAM5-HAM point (gold) and MAECHAM5-HAM band (orange). Vertical dashed black line indicates month of injection. 

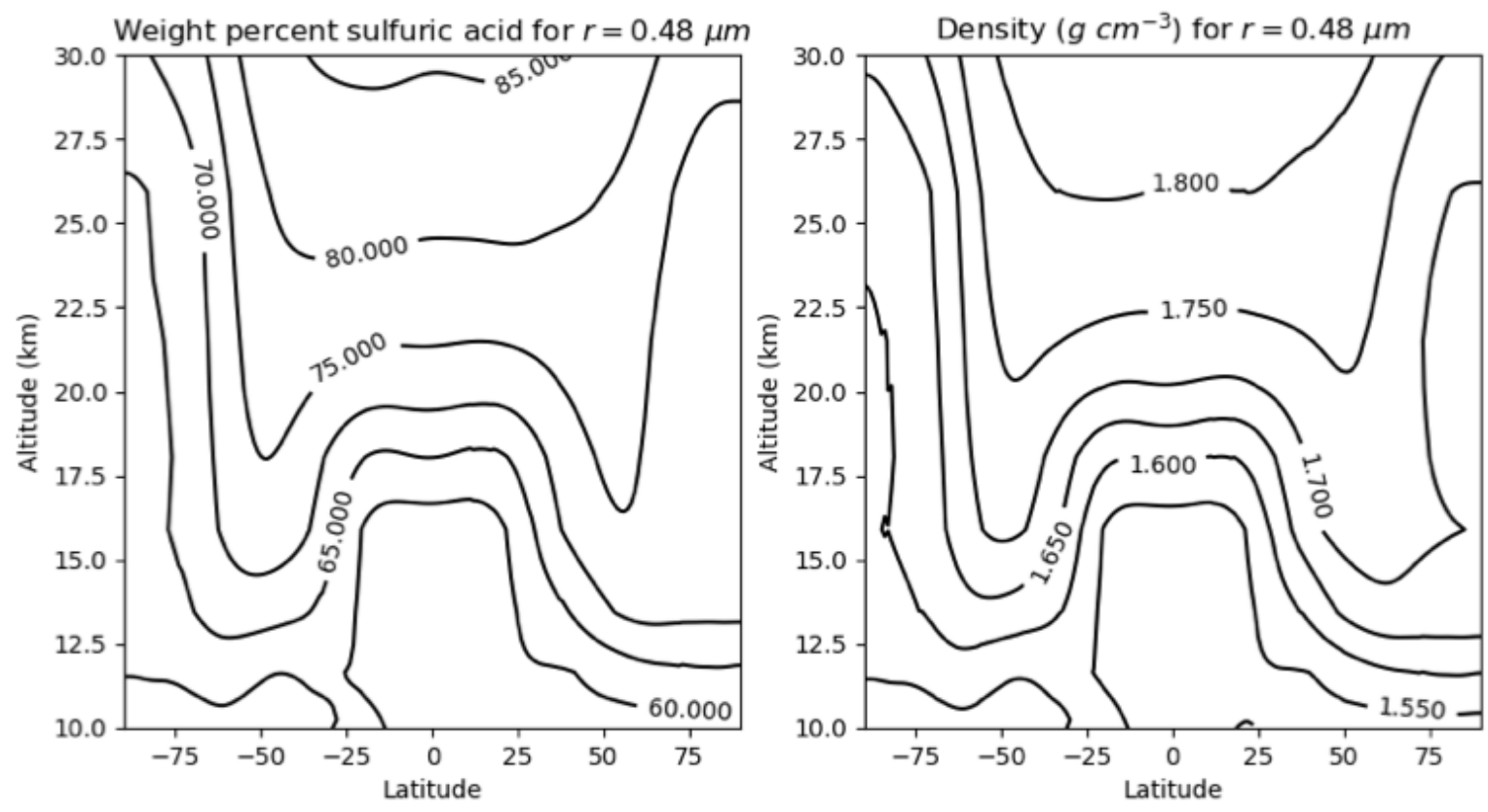

Figure S2: An example of the spatial variation of $\omega$ (left) and corresponding $\rho$ (right) from the Community Aerosol and Radiation Model for Atmospheres (CARMA) [Toon et al., 1988]. Figure courtesy of Parker Case. 

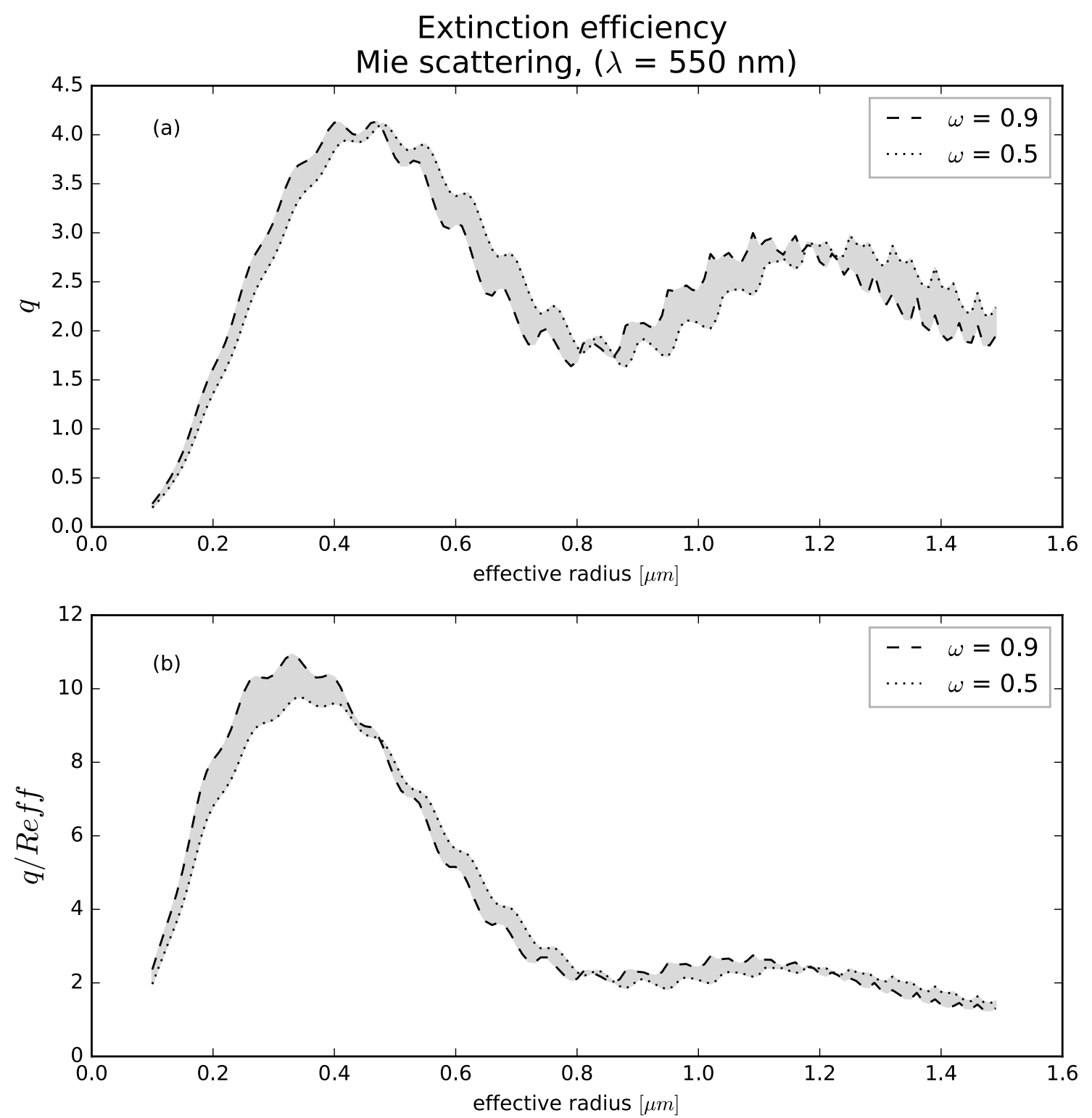

Figure S3: Extinction efficiency (a) and extinction efficiency divided by effective radius (b) from Mie scattering at the visible wavelength of 550nm as a function of effective radius. Values are calculated for $q$ from Mie theory using complex refractive indices corresponding to $\omega=0.5$ (dotted) through $\omega=0.9$ (dashed). 


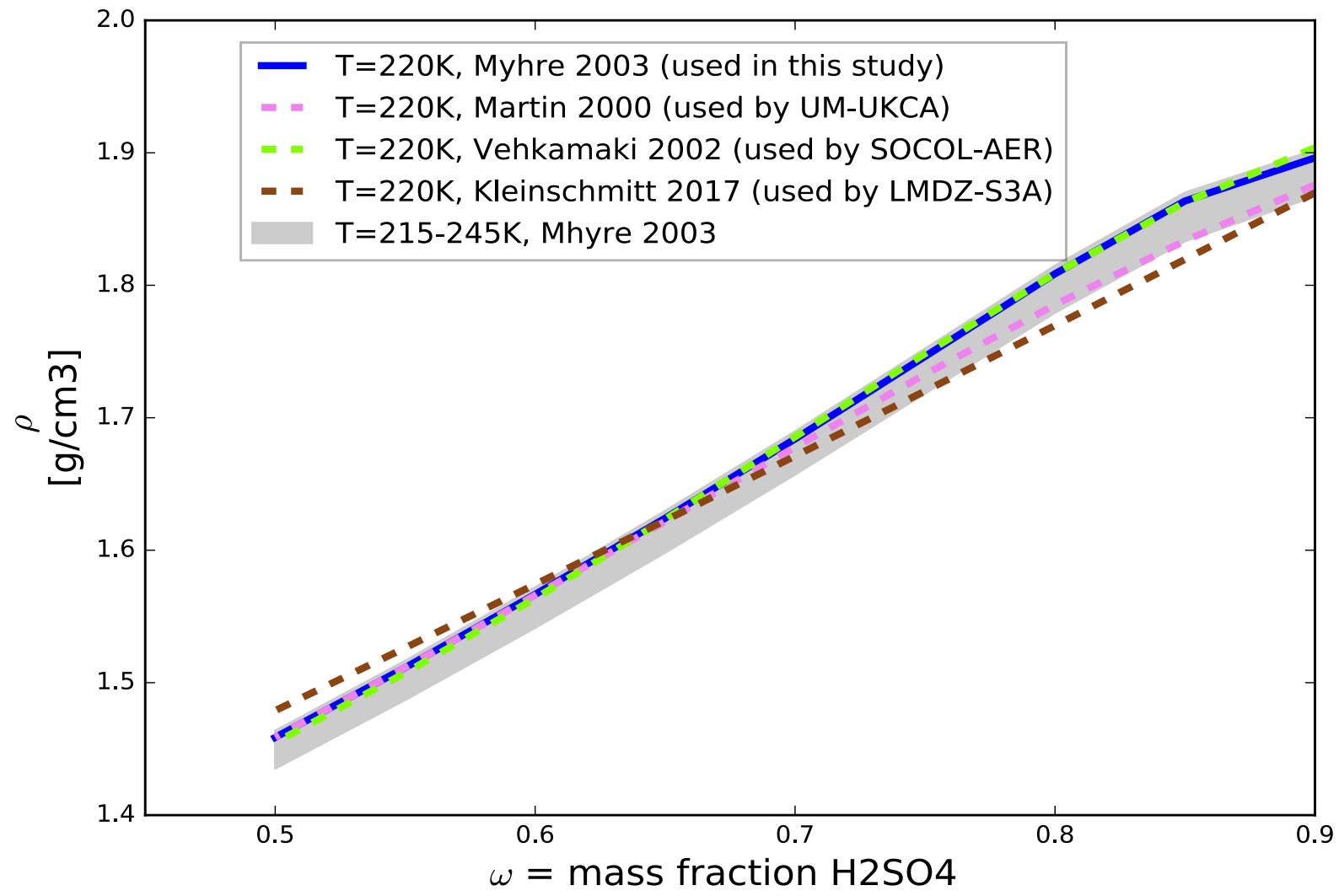

135

Figure S4: Polynomial functions used by other models to approximate $\rho$ from $\omega$ and temperature. Not shown: CESM-WACCM and MAECHAM5-HAM (see Appendix E). 